\title{
Mice lacking AMP-activated protein kinase $\alpha 1$ catalytic subunit have increased bone remodelling and modified skeletal responses to hormonal challenges induced by ovariectomy and intermittent PTH treatment
}

\author{
J Jeyabalan*, M Shah*, B Viollet ${ }^{1,2,3}$, J P Roux ${ }^{4}$, P Chavassieux ${ }^{4}$, M Korbonits ${ }^{5}$ and C Chenu \\ Department of Veterinary Basic Sciences, Royal Veterinary College, Royal College Street, London NW1 OTU, UK \\ ${ }^{1}$ INSERM, U1016, Institut Cochin, Paris, France \\ ${ }^{2}$ CNRS, UMR8104, Paris, France \\ ${ }^{3}$ Université Paris Decartes, Sorbonne Paris Cité, Paris, France \\ ${ }^{4}$ INSERM, UMR1033, Université de Lyon, Lyon, France \\ ${ }^{5}$ Department of Endocrinology, Barts and the London School of Medicine, Queen Mary University of London, London EC1M 6BQ, UK \\ (Correspondence should be addressed to J Jeyabalan; Email: jjeyabalan@rvc.ac.uk) \\ *(J Jeyabalan and M Shah are joint first authors)
}

\begin{abstract}
AMP-activated protein kinase (AMPK) is a key regulator of cellular and body energy homeostasis. We previously demonstrated that AMPK activation in osteoblasts increases in vitro bone formation while deletion of the Ampko1 (Prkaa1) subunit, the dominant catalytic subunit expressed in bone, leads to decreased bone mass in vivo. To investigate the cause of low bone mass in the Ampk $\alpha 1^{-1-}$ mice, we analysed bone formation and resorption in the tibia of these mice by dynamic histomorphometry and determined whether bone turnover can be stimulated in the absence of the Ampk 1 subunit. We subjected 12 -week-old $A m p k \alpha 1^{+/+}$ and $A m p k \alpha 1^{-/-}$mice to ovariectomy (OVX), intermittent PTH (iPTH) administration $(80 \mu \mathrm{g} / \mathrm{kg}$ per day, 5 days/week) or both OVX and iPTH hormonal challenges. Tibiae were harvested from these mice and bone micro-architecture was determined by micro-computed tomography. We show for the first time that Ampka1 $1^{-/-}$mice have a high bone
\end{abstract}

turnover at the basal level in favour of bone resorption. While both Ampko $1^{+/+}$and Ampk $\alpha 1^{-1-}$ mice lost bone mass after OVX, the bone loss in Ampk $\alpha 1^{-1-}$ mice was lower compared with controls. iPTH increased trabecular and cortical bone indexes in both ovariectomised Ampko $1^{+/+}$and Ampko $1^{-/-}$mice. However, ovariectomised Ampko $1^{-/-}$mice showed a smaller increase in bone parameters in response to iPTH compared with $A m p k \alpha 1^{+/+}$ mice. By contrast, non-ovariectomised Ampk $\alpha 1^{-1-}$ mice responded better to iPTH treatment than non-ovariectomised Ampko $1^{+/+}$mice. Overall, these data demonstrate that $A m p k \alpha 1^{-1-}$ mice are less affected by changes in bone turnover induced by OVX but respond better to the anabolic challenge induced by $\mathrm{iPTH}$. These results suggest that AMPK $\alpha 1$ activation may play a role in the hormonal regulation of bone remodelling.

Journal of Endocrinology (2012) 214, 349-358

\section{Introduction}

AMP-activated protein kinase (AMPK) is a sensor and regulator of energy homeostasis not only at the cellular level but also at the whole-body level where it mediates the central and peripheral effects of many hormones on the metabolisms of appetite, fat and glucose (Minokoshi et al. 2002, Yamauchi et al. 2002, Andersson et al. 2004, Banerjee et al. 2004, Minokoshi et al. 2004, Han et al. 2005, Kola et al. 2005, Yamauchi et al. 2008 and for reviews see Hardie et al. 2006, Kola et al. 2006 and Lage et al. 2008). It is a highly conserved, ubiquitously expressed serine/threonine heterotrimeric protein kinase consisting of a catalytic $\alpha$ subunit and regulatory $\beta$ and $\gamma$ subunits, all of which have several isoforms with differential tissue-specific expression patterns (Hardie et al. 2006, Kola et al. 2006, Steinberg \& Kemp 2009, Viollet et al. 2010, Hardie et al. 2011). AMPK senses the AMP/ATP ratio within the cell and is activated in response to environmental or nutritional stress factors that deplete intracellular ATP levels (Hardie et al. 2006, Hardie 2008, Steinberg \& Kemp 2009). AMP binding activates AMPK by two mechanisms, phosphorylation of the Thr-172 residue in 
the $\alpha$ subunit by upstream kinases and inhibition of dephosphorylation of Thr-172 by phosphatases (Hawley et al. 1996, 2003, 2005, Xiao et al. 2011). Once activated, it switches on catabolic pathways that generate ATP and switches off anabolic pathways that consume ATP.

In the last few years, several in vitro and in vivo studies have established that the AMPK signalling pathway could also play a role in bone physiology (Kanazawa et al. 2008, 2009, Kasai et al. 2009, Lee et al. 2010, Molinuevo et al. 2010, Quinn et al. 2010, Shah et al. 2010, Zhen et al. 2010, Jang et al. 2011a,b, Mai et al. 2011, Wu et al. 2011). We demonstrated that the AMPK $\alpha 1$ subunit is the dominant catalytic isoform expressed in bone and that AMPK activators stimulate in vitro bone nodule formation (Shah et al. 2010). Several other studies have confirmed that the two main AMPK activators, 5-aminoimidazole-4-carboxamide ribonucleoside (AICAR) and metformin, are osteogenic in vitro. They stimulate proliferation, differentiation and mineralisation of MC3T3-E1 osteoblastic cells (Kanazawa et al. 2008, 2009, Jang et al. 2011a,b, Mai et al. 2011), primary osteoblasts (Shah et al. 2010, Zhen et al. 2010) and bone marrow progenitor cells (Molinuevo et al. 2010, Wu et al. 2011). However, it was also reported that osteoblast differentiation is functionally associated with decreased AMPK activity (Kasai et al. 2009). The relationship between AMPK activation and bone resorption is also unclear. Activation of AMPK was shown to inhibit osteoclast formation and bone resorption in vitro, AMPK acting as a negative regulator of RANKL (Lee $e t$ al. 2010). By contrast, in vivo studies have shown that AICAR stimulates bone loss and bone turnover in male mice (Quinn et al. 2010). The evidence for a role of AMPK signalling in the regulation of bone mass is best supported by genetic studies. Our work has shown that Ampka1 (Prkaa1) knockout $\left(A m p k \alpha 1^{-/-}\right)$mice have a very low bone mass compared with the WT $\left(A m p k \alpha 1^{+/+}\right)$mice, both cortical and trabecular bone compartments being smaller in the Ampk $1^{-1-}$ mice (Shah et al. 2010). Similarly, Quinn et al. (2010) showed that germline deletions of either the $A M P K \beta 1$ or $\beta 2$ subunit resulted in reduced trabecular bone density and mass.

The underlying mechanism for the low bone mass in Ampko $1^{-1-}$ mice and the exact role of AMPK in bone remodelling in vivo have not yet been investigated. Bone remodelling occurs constantly at multiple locations within the skeleton and bone needs to balance energy in response to nutrient availability with growth and turnover. To address the role of AMPK in bone turnover, we subjected Ampk $\alpha 1^{-/-}$ and $A m p k \alpha 1^{+/+}$mice to two types of hormonal challenges that increase bone turnover, ovariectomy (OVX) that induces a negative bone balance and intermittent PTH (iPTH) treatment that is anabolic, and examined their effects on bone architecture in these mice. We show that Ampko $1^{-1-}$ mice have high bone turnover at basal level and that bone turnover in Ampka $1^{-/-}$mice is altered in response to OVX and $\mathrm{PPTH}$, suggesting that AMPK activation may modulate the hormonal regulation of bone remodelling.

\section{Materials and Methods}

\section{Animals}

Ampka1 knockout mice were generously provided by Dr Benoit Viollet (INSERM, U1016, Paris, France) and were generated as described previously (Jorgensen et al.

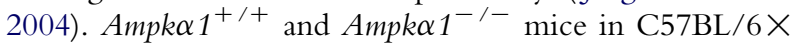
$129 / \mathrm{Sv}$ mixed background were used. All procedures were performed in accordance with the principles and guidelines established by the European Convention for the Protection of Laboratory Animals. All mice were maintained under a controlled temperature $\left(21^{\circ} \mathrm{C}\right)$ and lighting with $12 \mathrm{~h}$ light: $12 \mathrm{~h}$ darkness cycle and received a standard mouse chow diet and water ad libitum. The knockout mice do not show any obvious metabolic phenotypes and their body weight was unaffected (Jorgensen et al. 2004).

\section{Hormonal challenges}

Three independent experiments were carried out to determine the response of bone to hormonal challenges in Ampka1 knockout mice. In study 1, 12-week-old Ampk $\alpha 1^{+/+}$and Ampk $\alpha 1^{-/-}$mice $(n=7 /$ group) were either ovariectomised or sham operated. Tibiae were collected from these mice 6 weeks after OVX for microcomputed tomography (micro-CT) analysis. For measurement of dynamic bone formation parameters, mice in this study were i.p. injected with calcein (Sigma-Aldrich) and alizarin red complexone (Sigma-Aldrich), at days 6 and 3, respectively, before killing. For study 2, 12-week-old Ampko1 $1^{+/+}$and Ampko1 $1^{-/-}$mice $(n=8 /$ group) were all ovariectomised and immediately treated for 4 weeks with s.c. injection of either $80 \mu \mathrm{g} / \mathrm{kg}$ per day, 5 days/week, PTH (human PTH (1-34; Bachem, Inc., Torrance, CA, USA) dissolved in $1 \mathrm{mM} \mathrm{HCl}$ containing $0 \cdot 2 \% \mathrm{BSA}$ ) or saline. For study 3, 12-week-old Ampk $1^{+/+}$and Ampko $1^{-/-}$mice $(n=10-11 /$ group $)$ were treated with s.c. injection of either $80 \mu \mathrm{g} / \mathrm{kg}$ per day, 5 days/week, iPTH or saline. For all mice, body weight was measured at the beginning of week 13 (i.e. on day of sham operation, OVX or at the beginning of iPTH treatment) and at the end of the experiment. Left and right tibiae were harvested from these mice for micro-CT (studies 1, 2 and 3) and bone histomorphometric analyses (study 1) respectively. Femora were collected for western blot and RT-PCR analyses.

\section{Histomorphometry analysis of tibia}

Right tibia from sham-operated Ampk $\alpha 1^{+/+}$and $A m p k \alpha 1^{-1-}$ mice from study 1 were fixed in 10\% neutral-buffered formalin for 24-72 h, dehydrated and embedded in pure methyl methacrylate at low temperature to preserve enzymatic activity (Chappard et al. 1987). Unstained $8 \mu \mathrm{m}$-thick sections were used for fluorescence 
microscopy to assess mineral apposition rate (MAR, $\mu \mathrm{m} /$ day). Mineralising surfaces were expressed as double + half single labelled surfaces per bone surfaces (MS/BS, \%) and the bone formation rate was calculated as MS/BS $\times$ MAR $(B F R / B S$, $\mu \mathrm{m}^{3} / \mu \mathrm{m}^{2}$ per day; Chavassieux et al. 1997). Alternatively, sections were stained for tartrate-resistant acid phosphatase (TRAP; Leucognost SP, Merck) and counterstained with Mayer's hemalum solution. Goldner's trichrome staining was performed to determine adipocyte number per tissue area. Histomorphometric parameters were measured on the trabecular bone of the metaphysis, on a region of interest consisting of $2 \mathrm{~mm}$ width below the growth plate. Measurements were performed using an Image Analysis Software (Bone, Explora Nova, La Rochelle, France). Histomorphometric parameters were reported in accordance with the ASBMR Committee nomenclature (Parfitt et al. 1987).

\section{Micro-CT analysis of tibia}

Left tibia was fixed in 10\% neural-buffered formalin for $24-72 \mathrm{~h}$ and stored in $70 \%$ ethanol at $4{ }^{\circ} \mathrm{C}$. They were scanned with high-resolution $(5 \mu \mathrm{m}$ pixel size $)$ micro-CT (Skyscan 1172, Kontich, Belgium), as described previously (Shah et al. 2010). The whole tibia was reconstructed using NRecon v.1.4.4.0 (Skyscan) and bone histomorphometric analyses in 2- and 3-dimensions (2D and 3D) were performed by Skyscan Software (CT-Analyser v.1.5.1.3). For the analysis of trabecular bone, the cortical shell was excluded by operator-drawn regions of interest and 3D algorithms were used to determine the relevant parameters that included bone volume (BV) percentage (BV/tissue volume (TV), \%), direct trabecular thickness (Tb.Th) and spacing, trabecular number (Tb.N), structure model index (SMI), trabecular bone pattern factor (TBPf) and the degree of anisotropy (DA). Analysis of cortical bone was performed using a $0.49 \mathrm{~mm}$ long segment (or 100 tomograms) at 37\% of the tibias' length from the proximal end. For analysis of the cortical bone compartment, $2 \mathrm{D}$ computation was used and parameters were determined for each one of the 100 tomograms and then averaged. They included periosteal perimeter (Ps.Pm), endosteal perimeter (Ec.Pm) and cortical thickness (Ct.Th).

\section{$R N A$ extraction and RT-PCR analysis}

Total RNA was isolated from femora and femoral muscles

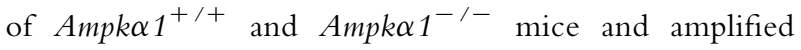
using subunit-specific primers, as described previously (Shah et al. 2010).

\section{Protein extraction and western blot analysis}

For the isolation of total proteins, right and left femora from Ampko $1^{+/+}$and Ampk $\alpha 1^{-/-}$mice were carefully dissected, all their surrounding musculature removed leaving the periosteum intact. The cartilaginous ends of the bones were separated and the remaining femoral shafts were flushed with PBS to remove the marrow. The femoral shafts were then snap-frozen and pulverised under liquid nitrogen using a mortar and pestle and then lysed in cold denaturing lysis buffer (2\% SDS, $2 \mathrm{M}$ urea, $8 \%$ sucrose, $20 \mathrm{mM}$ sodium glycerophosphate, $1 \mathrm{mM}$ sodium fluoride, and $5 \mathrm{mM}$ sodium orthovanadate). Proteins were denatured by boiling for $5 \mathrm{~min}$ and concentrations were determined by BCA protein assay. Two micrograms of proteins were size fractionated using SDS-PAGE and electrotransferred onto Protran nitrocellulose membranes (Schliecher and Schuell, Dassel, Germany). Membranes were blocked for $1 \mathrm{~h}$ in $0 \cdot 2 \%(\mathrm{w} / \mathrm{v})$ I-block (Topix, Bedford, MA, USA), before being incubated with primary antibodies. The blots were incubated overnight at $4{ }^{\circ} \mathrm{C}$ with antibodies against total AMPK $\alpha 1 / 2$ (tAMPK $\alpha 1 / 2$, rabbit), phospho-(Thr-172)AMPK $\alpha 1 / 2$ (pAMPK $\alpha 1 / 2$, rabbit) (New England Biolabs, Hitchin, UK) and $\beta$-actin (goat) (Dako, Ely, UK), all added at a 1:1000 dilution. The following secondary antibodies were used: goat anti-rabbit (New England Biolabs) against tAMPK and pAMPK $\alpha 1 / 2$ and rabbit anti-goat (Dako) against $\beta$-actin antibody, both at 1:2500 dilution at room temperature for $1 \mathrm{~h}$. Proteins were visualised using the enhanced chemiluminescence (ECL) detection system (GE Healthcare UK Ltd., Little Chalfont, UK). The intensity of the specific bands was quantified by densitometry using Image J Software.

\section{Statistical analysis}

The results are presented as mean \pm S.E.M. Comparisons between groups for all the data were performed using nonparametric Mann-Whitney $U$ test. Differences were considered statistically significant at $P<0 \cdot 05$. All statistical analyses were performed using GraphPad Prism Software (GraphPad Software, Inc., La Jolla, CA, USA).

\section{Results}

Female Ampk $\alpha 1^{-/-}$mice have decreased bone mass and increased bone remodelling

While our previous analysis of bone architecture in Ampko $1^{-/-}$ mice was done in males (Shah et al. 2010), we confirmed with the present experiments that female Ampko $1^{-/-}$mice have a similar low bone mass phenotype compared with Ampka $1^{+/+}$mice. The micro-CT measurements of trabecular and cortical parameters in tibia of non-OVX adult female mice (Fig. $1 \mathrm{~A}$ and $\mathrm{B}$ ) showed that the Ampko $1^{-1-}$ mice had significantly lower BV/TV, Tb.N and Ct. Th compared with Ampko $1^{+/+}$mice. Ampk $\alpha 1^{-/-}$ mice also showed a significant increase in SMI, a parameter reflecting trabecular shape, plate to rod elements $\left(A m p k \alpha 1^{+/+}, 1 \cdot 19 \pm 0 \cdot 15\right.$ vs Ampka $1^{-/-}, 1.69 \pm 0 \cdot 07$; $P<0 \cdot 05)$, compared with Ampka1 $1^{+/+}$mice. There were statistically non-significant increases in trabecular separation $\left(A m p k \alpha 1^{+/+}, \quad 0 \cdot 30 \pm 0 \cdot 05 \mathrm{~mm}\right.$ vs Ampka $1^{-/-}, 0 \cdot 47$ $\pm 0.05 \mathrm{~mm} ; P=0.073$ ) and TBPf (Fig. 1A) in Ampko $1^{-/-}$ 
A
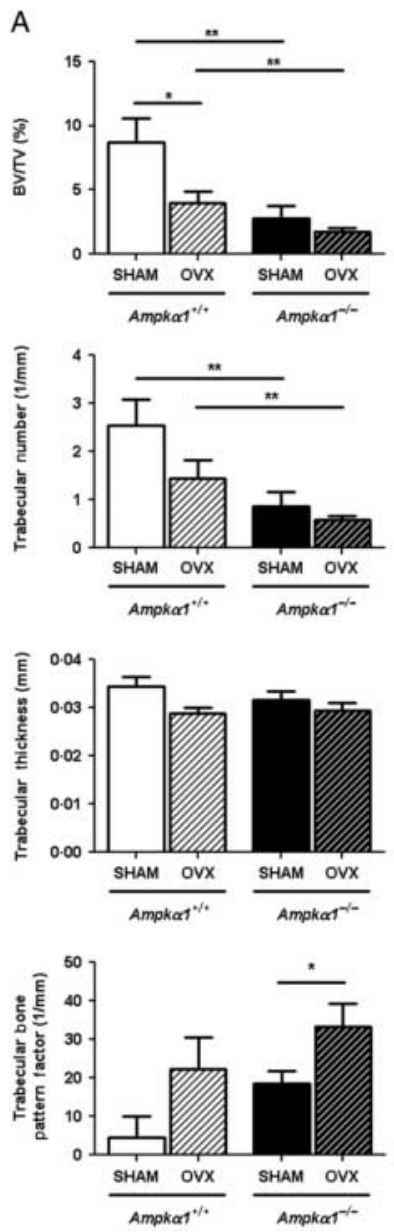

Figure 1 Effect of ovariectomy (OVX) on trabecular and cortical

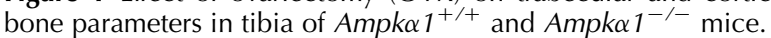
(A) Trabecular bone parameters in Ampk $\alpha 1^{+/+}$and Ampk $\alpha 1^{- \text {- }}$ mice that have undergone OVX or sham operation. (B) Cortical bone parameters in Ampk $\alpha 1^{+/+}$and Ampk $\alpha 1^{-/-}$mice subjected to OVX or sham operation. Values are mean \pm S.E.M. of $n=7$ mice/group, $* P<0 \cdot 05,{ }^{* *} P<0 \cdot 01$.

mice, suggesting poor trabecular interconnection. The DA reflecting trabecular structure $\left(A m p k \alpha 1^{+/+}, 1 \cdot 64 \pm 0 \cdot 10\right.$ vs Ampko $\left.1^{-1-}, 2 \cdot 57 \pm 0 \cdot 90 ; P=1 \cdot 000\right)$ and Ps.Pm and Ec.Pm (Fig. 1B) were not significantly different between the Ampko $1^{+/+}$and Ampko $1^{-1-}$ mice. These changes in the trabecular and cortical parameters of female Ampk $\alpha 1^{-/-}$ mice are similar to those observed in male $A m p k \alpha 1^{-/-}$mice (Shah et al. 2010). The trabecular architecture in Ampk $\alpha 1^{-/-}$ mice, characterised by increased SMI, trabecular separation and TBPf and lower BV/TV are similar to the changes seen during ageing and osteoporosis, suggesting an altered bone remodelling at basal level in these mice. To determine the cause of the low bone mass in $A m p k \alpha 1^{-1-}$ mice and whether bone remodelling is affected in these mice at basal level, we examined bone formation and resorption in the tibia of those mice, using bone histomorphometry. Analysis of BFR using double fluorescence labelling showed that the Ampk $\alpha 1^{-1-}$ mice had a higher BFR than $A m p k \alpha 1^{+/+}$mice (Fig. 2A), but this was not significant $(P=0 \cdot 095)$. The percentage of TRAP-positive surfaces (osteoclasts surfaces) was significantly higher in the Ampko $1^{-1-}$ mice compared with Ampko $1^{+/+}$mice (Fig. 2B). These results suggest that the Ampk $\alpha 1^{-1-}$ mice have a higher bone turnover compared with their Ampka1 $1^{+/+}$littermates in favour of bone resorption. In addition, the Ampk $\alpha 1^{-/-}$mice had twice the number of adipocytes than the $A m p k \alpha 1^{+/+}$mice within the bone marrow but, due to a large variation between animals, the difference was not significant (Fig. 2C).
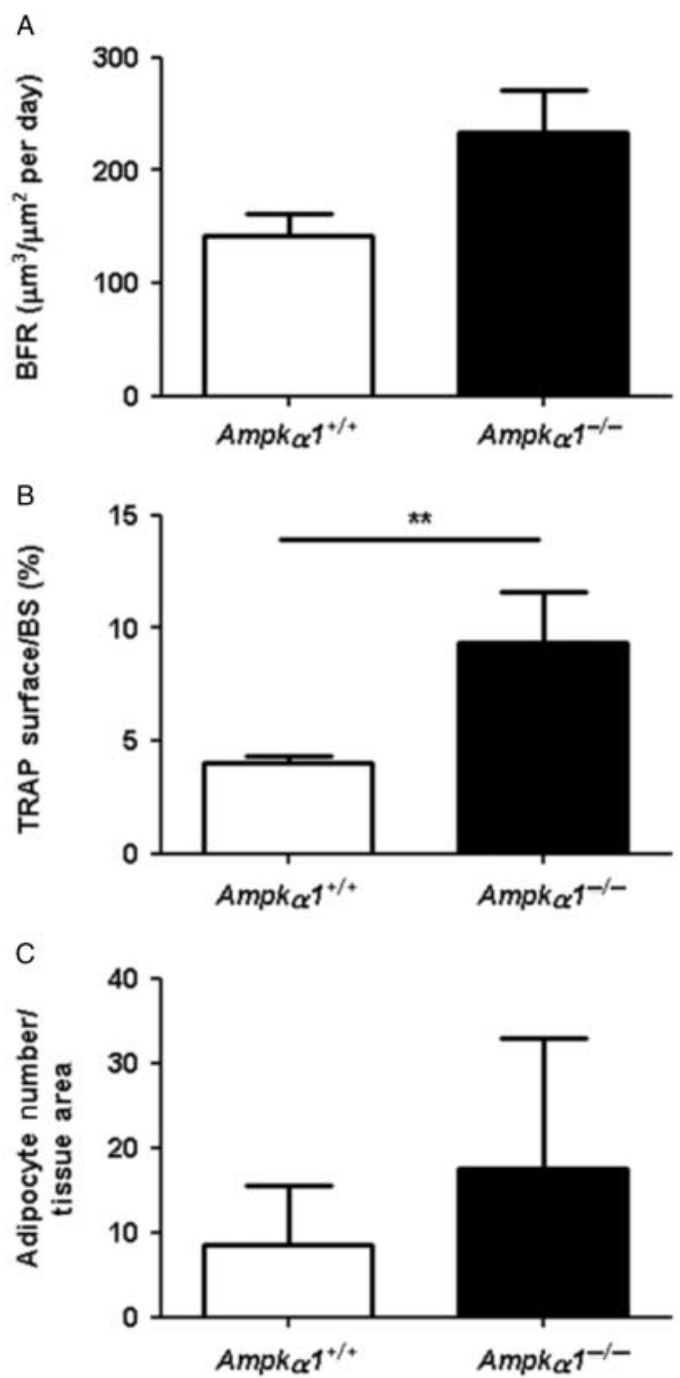

Figure 2 Dynamic bone histomorphometry analyses in Ampk $\alpha 1^{+/+}$and Ampk $\alpha 1^{-/-}$mice. (A) BFR, (B) percentage of TRAP surfaces and (C) number of adipocytes per tissue area in 16-week-old Ampk $\alpha 1^{+/+}$and Ampk $\alpha 1^{-1-}$ mice. Values are mean \pm S.E.M. of $n=7$ mice/group, $* * P<0 \cdot 01$. 
Ovariectomy (OVX) induces bone loss in Ampk $\alpha 1^{+/+}$and Ampk $\alpha 1^{-1-}$ mice

To investigate the skeletal response of $A m p k \alpha 1^{-/-}$mice to OVX, known to stimulate bone remodelling, OVX or sham operations were performed in $A m p k \alpha 1^{+/+}$and $A m p k \alpha 1^{-1-}$ mice. All the mice from these groups have gained weight throughout the treatment period. However, comparison of weight changes (from the day of sham or OVX operation to day of sacrifice, i.e. over the 6-week period) between the groups did not detect any statistically significant differences (sham- $A m p k \alpha 1^{+/+}, 1.37 \pm 0.61 \mathrm{~g}$ vs OVX-Ampk $\alpha 1^{+/+}$, $1.66 \pm 0.42 \mathrm{~g}$; sham- $A m p k \alpha 1^{-1-}, 1.76 \pm 0.25 \mathrm{~g}$ vs OVXAmpka $\left.1^{-/-}, 1.54 \pm 0.30 \mathrm{~g}\right)$. In addition, there was no significant difference in weight change between shamAmpk $\alpha 1^{+/+}$and sham-Ampk $\alpha 1^{-/-}$mice. Tibial bone length was also not significantly different between $A m p k \alpha 1^{+/+}$ or $A m p k \alpha 1^{-1-}$ mice (data not shown).

As expected, OVX induced bone loss in Ampk $\alpha 1^{+/+}$ mice. These mice showed a significant decrease in $\mathrm{BV} / \mathrm{TV}$ after OVX (Fig. 1A). Tb.N $(P=0 \cdot 097)$ and thickness $(P=0.073)$ were also decreased in the $A m p k \alpha 1^{+/+}$mice after OVX, while TBPf was increased $(P=0 \cdot 165)$, although these parameters were not statistically significant (Fig. 1A). Analysis of cortical parameters demonstrated a significant increase in Ec.Pm and Ps.Pm in Ampk $\alpha 1^{+/+}$mice after OVX (Fig. 1B). By contrast, Ct.Th was significantly decreased after OVX in these mice (Fig. 1B).

Ovariectomy also induced alterations in both the trabecular and cortical bones in the Ampko $1^{-1-}$ mice, but the effects were moderate, indicating that the bone response to OVX in these mice is attenuated (Fig. 1). Ampko $1^{-1-}$ mice showed a significant increase in TBPf, but there were nonstatistically significant decreases in BV/TV, Tb.N and thickness after OVX in these mice (Fig. 1A). Cortical parameters were not significantly affected in the Ampko $1^{-/-}$ mice after OVX (Fig. 1B).

iPTH increases bone formation in ovariectomised Ampk $\alpha 1^{+/+}$ and Ampk $\alpha 1^{-/-}$mice

To determine whether PTH treatment overcomes the bone

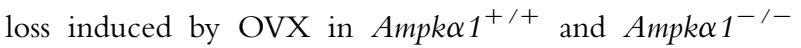
mice, those mice were ovariectomised and then treated with iPTH or saline for 4 weeks. There was no difference in weight due to iPTH treatment in the ovariectomised Ampk $\alpha 1^{+/+}$ and Ampko $1^{-1-}$ mice (data not shown). Our results demonstrate that $\mathrm{iPTH}$ treatment alters trabecular and cortical bone indexes in both OVX-Ampk $\alpha 1^{+/+}$and OVX-Ampk $1^{-1-}$ mice (Fig. 3).

In OVX-Ampk $\alpha 1^{+/+}$mice, iPTH induced a significant increase in $\mathrm{BV} / \mathrm{TV}$ and $\mathrm{Tb} . \mathrm{N}$ and a significant decrease in TBPf (Fig. 3A), trabecular separation (Saline OVXAmpk $\alpha 1^{+++}, 0.46 \pm 0.03 \mathrm{~mm}$ vs iPTH OVX $-A m p k \alpha 1^{+/+}$, $0 \cdot 20 \pm 0.01 \mathrm{~mm} ; \quad P<0 \cdot 0005$ ) and SMI (Saline OVXAmpk $\alpha 1^{+/+}, 2 \cdot 37 \pm 0 \cdot 04$ vs iPTH OVX-Ampk $\alpha 1^{+/+}$,

$1 \cdot 38 \pm 0 \cdot 09 ; P<0 \cdot 0005)$. In the cortical compartment, Ps.Pm and Ec.Pm were significantly increased as a result of iPTH treatment in the OVX-Ampk $\alpha 1^{+/+}$mice, while Ct.Th was not affected (Fig. 3B).

Similarly, in OVX-Ampk $\alpha 1^{-/-}$mice, iPTH significantly increased $\mathrm{BV} / \mathrm{TV}$ and $\mathrm{Tb} . \mathrm{N}$, but significantly decreased Tb.Th (Fig. 3A), separation (Saline OVXAmpk $1^{-/-}, 0 \cdot 29 \pm 0.01 \mathrm{~mm}$ vs iPTH OVX-Ampk $\alpha 1^{-/-}$, $0.23 \pm 0.01 \mathrm{~mm} ; \quad P<0.05$ ) and SMI (Saline OVXAmpko $1^{-1-}, 2 \cdot 01 \pm 0 \cdot 05$ vs iPTH OVX-Ampk $\alpha 1^{-1-}$, $1 \cdot 53 \pm 0 \cdot 13 ; P<0 \cdot 05)$. Within the cortical compartment of these mice, Ps.Pm was also significantly increased by iPTH

A
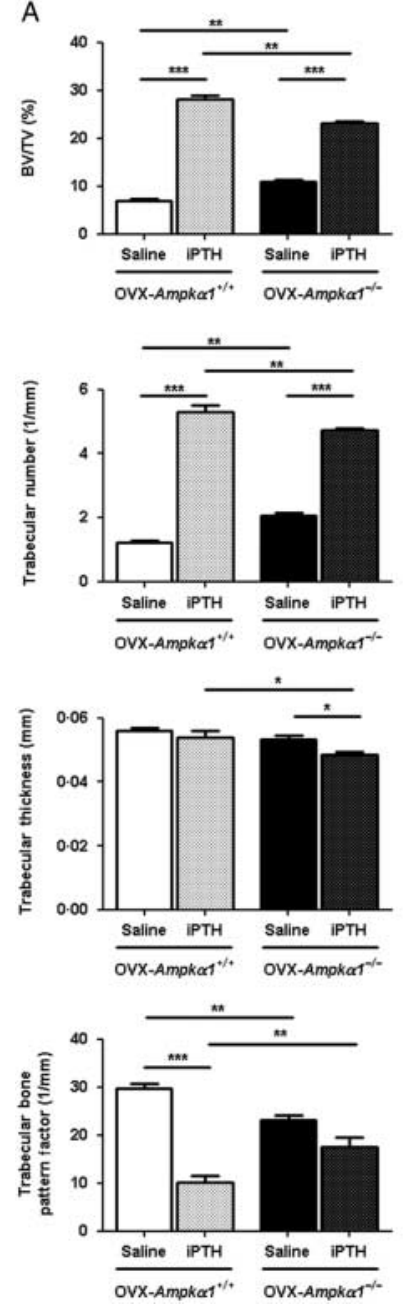

Figure 3 Effect of 4 weeks of iPTH treatment on trabecular and cortical bone parameters in tibia of ovariectomised Ampk $\alpha 1^{+/+}$ and $A m p k \alpha 1^{-1-}$ mice. (A) Trabecular bone parameters in ovariectomised Ampk $\alpha 1^{+/+}\left(\mathrm{OVX}-A m p k \alpha 1^{+/+}\right)$and Ampk $\alpha 1^{-/-}$ (OVX-Ampk $\left.\alpha 1^{-1-}\right)$ mice that have been treated with iPTH or saline. (B) Cortical bone parameters in OVX-Ampk $\alpha 1^{+/+}$and OVX-Ampk $\alpha 1^{-1-}$ mice subjected to iPTH or saline treatment. Values are mean \pm S.E.M. of $n=8$ mice/group, $* P<0 \cdot 05,{ }^{* *} P<0 \cdot 01$, $* * * P<0 \cdot 001$. 
treatment but not the other parameters (Fig. 3B). Our results illustrate that the ovariectomised $A m p k \alpha 1^{-/-}$mice have an attenuated response to iPTH treatment compared with Ampk $\alpha 1^{+/+}$mice.

iPTH increases bone formation in Ampk $\alpha 1^{+/+}$and Ampk $\alpha 1^{-/-}$mice

We then analysed the effect of iPTH in non-ovariectomised Ampko $1^{+/+}$and Ampk $\alpha 1^{-/-}$mice. Four weeks of iPTH treatment in the non-ovariectomised Ampko $1^{+/+}$mice induced mild increases in bone formation in the trabecular and cortical compartments (Fig. 4). Within the trabecular compartment, the only statistically significant change

A
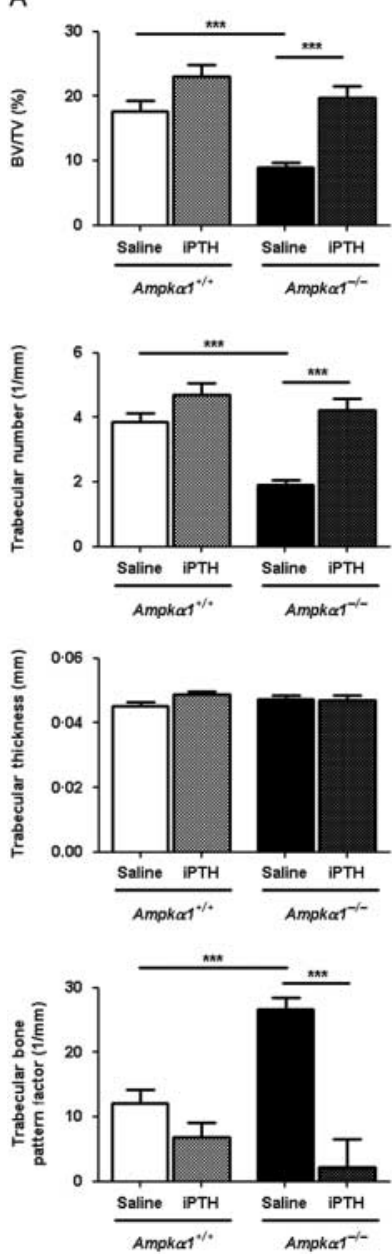

Figure 4 Effect of 4 weeks of iPTH treatment on trabecular and cortical bone parameters in tibia of Ampk $\alpha 1^{+/+}$and Ampk $\alpha 1^{-/-}$ mice. (A) Trabecular bone parameters in Ampk $\alpha 1^{+/+}$and Ampk $\alpha 1^{-1-}$ mice that have been treated with either iPTH or saline for 4 weeks. (B) Cortical bone parameters in Ampk $\alpha 1^{+/+}$and Ampk $\alpha 1^{-/-}$mice treated with iPTH or saline for 4 weeks. Values are mean \pm s.E.M. of $n=10-11$ mice/group, $* P<0 \cdot 05,{ }^{* * *} P<0 \cdot 001$. induced by iPTH was a decrease in DA (saline-Ampk $\alpha 1^{+/+}$, $1 \cdot 81 \pm 0 \cdot 04$ vs $\left.\mathrm{iPTH}-A m p k \alpha 1^{+/+}, 1 \cdot 69 \pm 0 \cdot 04 ; P<0 \cdot 05\right)$. There were non-significant increases in BV/TV $(P=0 \cdot 057)$, Tb.N $(P=0.076)$ and thickness $(P=0.066$; Fig. 4A). iPTH also induced a significant increase in $\mathrm{Ct}$. Th in the Ampko $1^{+/+}$mice (Fig. 4B), while the other cortical bone parameters were not significantly affected. By contrast, in the $A m p k \alpha 1^{-/-}$mice, iPTH induced a significant increase in BV/TV and Tb.N and a significant decrease in TBPf (Fig. 4A), trabecular separation (saline-Ampk $\alpha 1^{-/-}$, $0 \cdot 25 \pm 0 \cdot 01 \mathrm{~mm}$ vs iPTH-Ampk $\alpha 1^{-/-}, 0 \cdot 19 \pm 0 \cdot 01 \mathrm{~mm}$; $P<0 \cdot 005)$, SMI (saline-Ampk $\alpha 1^{-/-}, 2 \cdot 07 \pm 0.08$ vs iPTH-Ampk $\left.\alpha 1^{-/-}, \quad 1 \cdot 12 \pm 0 \cdot 18 ; \quad P<0 \cdot 0005\right)$ and DA (saline-Ampk $\alpha 1^{-/-}, 1.98 \pm 0.05$ vs iPTH-Ampk $\alpha 1^{-/-}$, $1.59 \pm 0.07 ; P<0.005)$. In the cortical compartment, it significantly increased Ec.Pm but had no effect on the other parameters (Fig. 4B). Surprisingly, in this experiment, $\mathrm{Ct}$.Th was not decreased in the saline $A m p k \alpha 1^{-/-}$mice compared with $A m p k \alpha 1^{+/+}$mice, in contrast to Fig. 1 and our previous results (Shah et al. 2010).

The comparison of changes in trabecular and cortical parameters due to iPTH treatment between $A m p k \alpha 1^{+/+}$and $A m p k \alpha 1^{-/-}$mice shows that PTH induces a greater increase in bone in the non-ovariectomised $A m p k \alpha 1^{-/-}$mice.

iPTH induces $A M P K \alpha$ phosphorylation in Ampk $\alpha 1^{+/+}$mice

To determine whether iPTH treatment could affect bone AMPK activity, AMPK $\alpha 1 / 2$ subunit phosphorylation was determined by western blot analysis of proteins extracted from femora of mice from study 2 treated with saline or iPTH. The antibodies we used against phosphorylated AMPK $\alpha$ and total AMPK $\alpha$ do not differentiate between the $\alpha 1$ and $\alpha 2$ subunits. Our western blot analysis showed that iPTH induced a significant increase in pAMPK $\alpha 1 / 2$ levels in Ampko $1^{+/+}$mice but not in $A m p k \alpha 1^{-/-}$mice (Fig. 5Ai and ii). We previously showed that there is a very low level expression of $\alpha 2$ subunit in bone at basal conditions (Shah et al. 2010). To confirm that the absence of $\alpha 1$ transcript in the Ampko $1^{-/-}$mice does not induce a compensatory increase in $\alpha 2$ expression in bone, we examined the expression of $\alpha$ subunits in bones from $A m p k \alpha 1^{-/-}$mice and showed that there was no overexpression of $\alpha 2$ in the bones of these mice (Fig. 5B).

\section{Discussion}

We show in this study that the low bone mass observed in male $A m p k \alpha 1^{-1-}$ mice is also observed in female $A m p k \alpha 1^{-/-}$ mice and is due to an increase in bone formation and resorption with an imbalance in favour of resorption. In addition, our results reveal that bone turnover induced by OVX and iPTH hormonal challenges is moderately reduced in the $A m p k \alpha 1$ subunit knockout mice. However, the skeletal responses to OVX and $\mathrm{iPTH}$ in these mice were different 
A

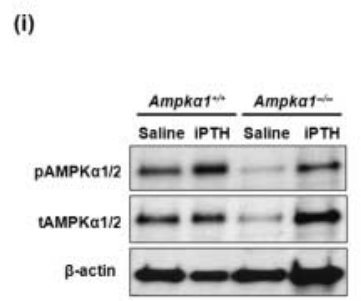

B

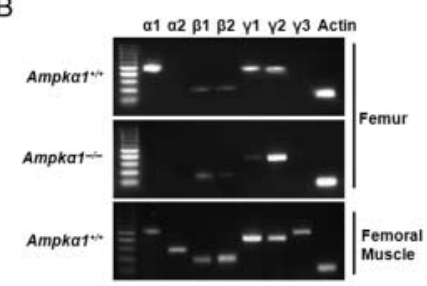

Figure 5 Effect of iPTH treatment on AMPK $\alpha 1 / 2$ phosphorylation in bone of ovariectomised Ampk $\alpha 1^{+/+}$and Ampk $\alpha 1^{-/-}$mice. (A, i) Western blot analysis of $\mathrm{pAMPK} \alpha 1 / 2$ and tAMPK $\alpha 1 / 2$. Proteins were extracted from femora of 16-week-old OVX-Ampk $\alpha 1^{+/+}$and OVX-Ampk $\alpha 1^{-1-}$ mice from study 2 and probed with polyclonal antibodies directed against pAMPK $\alpha 1 / 2$, tAMPK $\alpha 1 / 2$ and $\beta$-actin. Representative immunoblots are shown, which were repeated three times with similar results. (ii) Graph showing the ratio of pAMPK $\alpha 1 / 2$ to tAMPK $\alpha 1 / 2$ relative to $\beta$-actin determined by densitometry analysis of western blot data using Image J Software. Proteins were extracted from femora of two mice per group and western blot analyses were carried out in triplicates. Values are mean \pm S.E.M., $* P<0 \cdot 05$. (B) RT-PCR analysis of RNA extracted from femora of Ampk $\alpha 1^{+1+}$ and Ampk $\alpha 1^{-/-}$mice showing differential subunit expression pattern. Expression pattern of AMPK subunits in femoral muscle from Ampk $\alpha 1^{+/+}$mice was carried as a control.

from their WT littermate controls, suggesting that AMPK activation mediates the effects of these hormones on bone turnover.

The increased BFR and resorption surfaces in the Ampko $1^{-1-}$ mice suggest increased bone remodelling. This accelerated bone turnover in favour of bone resorption could explain their low bone mass at basal level. Interestingly, deletion of AMPK $\beta$ subunits in mice also reduced bone mass and the authors did not observe any reduction in osteoblast or osteoclast numbers in these mice, suggesting that the low bone mass observed in $A m p k \beta 1$ and 2 knockout mice could be due to changes in bone cellular functions (Quinn et al. 2010). Our results, although not statistically significant, show an increase in BFR and MS, reflecting active bone formation, which could be due to an increase in the birth of new remodelling units and/or an increase in the lifespan of these remodelling units. At the cellular level, this could be the result of an enhanced differentiation of osteoprogenitors into mature osteoblasts or an increased lifespan of osteoblasts. This increase in bone formation was an unexpected finding as several in vitro studies indicate that AMPK activation stimulates bone formation (Kanazawa et al. 2008, 2009,
Molinuevo et al. 2010, Shah et al. 2010, Jang et al. 2011a,b, Mai et al. 2011, Wu et al. 2011). We also show in this paper a trend towards an increase in marrow adipocyte numbers in bones of $A m p k \alpha 1^{-/-}$mice, which could suggest a potential interaction between AMPK signalling in fat and bone, and this will need to be further investigated. Our results indicate that bone resorption is increased in $A m p k \alpha 1^{-/-}$ mice, suggesting that AMPK $\alpha 1$ activation inhibits bone resorption. Indeed, it has been shown that AMPK acts as a negative regulator of RANKL in bone marrow macrophages, and inhibition of AMPK increases RANKL-dependent formation of TRAP-positive multinucleated cells and bone resorption area (Lee et al. 2010). This could therefore explain the increase in percentage of TRAP surfaces in Ampko $1^{-/-}$mice.

To clarify whether changes in basal bone cellular activities in $A m p k \alpha 1^{-1-}$ mice affect their responses to changes in bone turnover, we first submitted these mice to OVX. Loss of bone mass, trabecular thinning and increased trabecular separation are general features of bone after OVX (Parfitt et al. 1987, Compston et al. 1989). This is due to increased bone resorption, which exceeds bone formation at the initial stages (Lambers et al. 2012). Consistent with this, we observed deteriorated trabecular bone architecture in the Ampk $\alpha 1^{+/+}$mice after OVX. Furthermore, OVX caused endosteal bone resorption and periosteal bone apposition in these mice, which is consistent with the known effect of OVX on cortical bone architecture (Turner et al. 1987a,b). Weight gain is typically observed after OVX in rats and in humans after menopause (Lobo 2008, Tezval et al. 2011a). Although all mice gained weight during the 6-week experimental period, OVX did not induce significant weight gain in both the $A m p k \alpha 1^{+/+}$and $A m p k \alpha 1^{-/-}$mice. Body weight gain after OVX in mice is not always observed and may depend on the genetic background, as previously reported (Andersson et al. 2001, Bouxsein et al. 2005, Li et al. 2005, Iwaniec et al. 2006).

Our results illustrate that $A m p k \alpha 1^{-/-}$mice, similar to Ampk $\alpha 1^{+/+}$mice, can lose bone after OVX, although this bone loss was moderate compared with $A m p k \alpha 1^{+/+}$mice. This suggests that AMPK $\alpha 1$ is likely to play a role in bone resorption and remodelling induced by OVX. As bone mass is already very low at basal levels in the $A m p k \alpha 1^{-/-}$mice, there may be a protective mechanism to reduce the level of bone loss induced by OVX and to preserve the bone architecture without causing deleterious effects. One possibility for this mechanism could be the fact that there is less surface area for bone resorption. A study investigating OVX-induced bone loss in different inbred mouse strains revealed indeed that strains with low basal trabecular bone mass lose less bone compared with mice with high basal bone mass (Bouxsein et al. 2005). Alternatively, as bone remodelling is already very high in $A m p k \alpha 1^{-/-}$mice, they may be less sensitive to an increase in bone remodelling induced by oestrogen withdrawal. 
Intermittent administration of $\mathrm{PTH}$ is known to increase bone mass and improve bone architecture (Iida-Klein et al. 2002, Jiang et al. 2003, Brouwers et al. 2009, Recker et al. 2009). At the cellular level, iPTH has been shown to increase bone remodelling (Fox et al. 2006, Wade-Gueye et al. 2010) with bone formation exceeding resorption. To understand the bone responses of $A m p k \alpha 1^{-/-}$mice to anabolic (iPTH) stimuli, we first subjected ovariectomised $A m p k \alpha 1^{+/+}$ and Ampko $1^{-1-}$ mice to iPTH treatment for 4 weeks (study 2). Our results confirm previous studies showing that iPTH (1-34) can increase bone formation in ovariectomised rodents (Alexander et al. 2001, Fox et al. 2006, Wade-Gueye et al. 2010, Tezval et al. 2011a). We show that similar to OVX-Ampk $\alpha 1^{+/+}$mice, OVX-Ampk $\alpha 1^{-/-}$mice have an increase in trabecular BV and number as well as an augmented cortical bone mass in response to iPTH, confirming that osteoblast function is not severely affected in these Ampk $\alpha 1^{-/-}$mice. OVX-Ampk $\alpha 1^{-/-}$mice were, however, less affected than OVX-Ampk $\alpha 1^{+/+}$mice by the changes in bone turnover induced by $\mathrm{PTH}$, possibly because they lost less bone after OVX than their WT controls. We indeed found in this study that the trabecular bone mass in OVX-Ampk $\alpha 1^{-1-}$ mice was higher than that of OVX$A m p k \alpha 1^{+/+}$mice (Fig. 3), which contrasts with our first study (Fig. 1) where OVX-Ampk $\alpha 1^{-/-}$mice had lower trabecular bone mass than OVX-Ampk $\alpha 1^{+/+}$mice. This suggests that the $A m p k \alpha 1^{-/-}$mice in study 2 did not lose as much bone mass after OVX as those in study 1 . This discrepancy in the amount of bone loss after OVX between our two studies may be due to the time after OVX. In study 1 , bone mass was determined 6 weeks after OVX while in study 2 it was investigated after 4 weeks, and there are studies supporting a time-dependent bone loss after OVX ( $\mathrm{Li}$ et al. 2005, Iwaniec et al. 2006). It is also possible that the absence of AMPK $\alpha 1$ may have contributed to this delay in bone loss after OVX in the Ampk $\alpha 1^{-1-}$ mice.

To further investigate whether $A m p k \alpha 1^{-/-}$mice responded to the sole anabolic effect of iPTH, nonovariectomised $A m p k \alpha 1^{+/+}$and $A m p k \alpha 1^{-/-}$mice were treated with iPTH for 4 weeks (study 3 ). In nonovariectomised $A m p k \alpha 1^{+/+}$mice, iPTH induced a smaller increase in bone mass compared with mice that were ovariectomised, suggesting that OVX enhances the anabolic effect of iPTH on bone mass, as previously demonstrated (Andersson et al. 2001, Tezval et al. 2011b). By contrast, iPTH elicited a larger increase in bone mass in non-ovariectomised Ampko $1^{-/-}$mice compared with Ampk $\alpha 1^{+/+}$mice, possibly due to the low basal level of bone mass in these mice, enhancing the effect of iPTH. Interestingly, the comparison of the percentage of increased bone mass induced by $\mathrm{iPTH}$ in OVX-Ampk $1^{-/-}$mice (study 2) and nonOVX-Ampk $\alpha 1^{-1-}$ mice (study 3 ) showed that it is similar, in contrast to $A m p k \alpha 1^{+/+}$mice where there is about a tenfold decrease in the response to iPTH in non-OVX mice.

Our data suggest that the presence of the AMPK $\alpha 1$ subunit, and consequently AMPK activation in bone, is not essential for bone turnover but may contribute to the modulation of this process. We previously showed that the $\alpha 2$ subunit, in contrast to other tissues (Stapleton et al. 1996, Quinn et al. 2009, Shah et al. 2010), is not highly expressed in bone (Quinn et al. 2010, Shah et al. 2010). Furthermore, our results demonstrate that there is no compensatory up-regulation of $\alpha 2$ in bones of $A m p k \alpha 1^{-1-}$ mice. This is in contrast to the demonstration of an up-regulation of $\alpha 2$ in the soleus and extensor digitorum muscle in the Ampko $1^{-/-}$mice (Jorgensen et al. 2004). We cannot exclude, however, that this up-regulation of $\alpha 2$ in muscle and possibly in other tissues in these mice may have indirectly affected bone (Jorgensen et al. 2004).

As our study was performed with $A m p k \alpha 1^{-/-}$mice that are conventional whole-body knockout, we cannot exclude that the effects of the deletion of the $\alpha 1$ subunit observed in bone may be the result of indirect effects of AMPK deletion in other tissues. Ampk $\alpha 1^{-/-}$mice have been reported to have significantly reduced inguinal and epididymal fat weights compared with $A m p k \alpha 1^{+/+}$mice and a tendency for lower body weights (Daval et al. 2005), although this was not observed in our study or in other studies (Jorgensen et al. 2004, Viollet et al. 2009). No other metabolic phenotype was reported in these Ampka $1^{-/-}$mice and these mice have no changes in oestrogen levels. It is, however, unknown whether PTH levels are altered in these mice.

While the hormonal regulation of AMPK activation is well characterised in several tissues (Xue \& Kahn 2006, Dzamko \& Steinberg 2009, Lim et al. 2010), it has not been extensively studied in bone. Our previous work has shown that AMPK activity in bone cells could be regulated by the same hormones that regulate food intake and energy expenditure through AMPK activation in the brain and peripheral tissues (Shah et al. 2010). While our preliminary data in the osteoblastic cell line UMR-106 have shown no effect of oestrogen on AMPK activation (data not shown), our results show for the first time that iPTH increased the level of pAMPK $\alpha 1 / 2$ in vivo in the ovariectomised Ampk $\alpha 1^{+/+}$ mice, suggesting that PTH may activate AMPK signalling in bone, although this signalling pathway does not seem essential for the effect of PTH on bone formation. Further studies must, however, be carried out to elucidate downstream pathways and mechanism of action. PTH also induced a non-significant effect on phosphorylation of AMPK $\alpha 1 / 2$ in the $A m p k \alpha 1^{-/-}$mice, likely due to the phosphorylation of the $\alpha 2$ subunit, expressed at very low levels in bone.

In conclusion, we demonstrate that $A m p k \alpha 1^{-/-}$ mice have an increased bone turnover compared with Ampko $1^{+/+}$mice and can increase and decrease bone mass in response to anabolic and catabolic hormonal challenges, although these responses are modified. Taken together, our results indicate that AMPK $\alpha 1$ activity is not essential for bone turnover but may contribute to the regulation of bone remodelling. 


\section{Declaration of interest}

The authors declare that there is no conflict of interest that could be perceived as prejudicing the impartiality of the research reported.

\section{Funding}

This work was supported by the Wellcome Trust grant (grant reference: 086630) and a joint exchange grant between the Royal Society and CNRS (Centre national de la recherche scientifique).

\section{References}

Alexander JM, Bab I, Fish S, Muller R, Uchiyama T, Gronowicz G, Nahounou M, Zhao Q, White DW, Chorev M et al. 2001 Human parathyroid hormone 1-34 reverses bone loss in ovariectomized mice. Journal of Bone and Mineral Research 16 1665-1673. (doi:10.1359/jbmr.2001. 16.9.1665)

Andersson N, Lindberg MK, Ohlsson C, Andersson K \& Ryberg B 2001 Repeated in vivo determinations of bone mineral density during parathyroid hormone treatment in ovariectomized mice. Journal of Endocrinology 170 529-537. (doi:10.1677/joe.0.1700529)

Andersson U, Filipsson K, Abbott CR, Woods A, Smith K, Bloom SR, Carling D \& Small CJ 2004 AMP-activated protein kinase plays a role in the control of food intake. Journal of Biological Chemistry 279 12005-12008. (doi:10.1074/jbc.C300557200)

Banerjee RR, Rangwala SM, Shapiro JS, Rich AS, Rhoades B, Qi Y, Wang J, Rajala MW, Pocai A, Scherer PE et al. 2004 Regulation of fasted blood glucose by resistin. Science 303 1195-1198. (doi:10.1126/science.1092341)

Bouxsein ML, Myers KS, Shultz KL, Donahue LR, Rosen CJ \& Beamer WG 2005 Ovariectomy-induced bone loss varies among inbred strains of mice. Journal of Bone and Mineral Research 20 1085-1092. (doi:10.1359/JBMR. 050307)

Brouwers JE, van Rietbergen B, Huiskes R \& Ito K 2009 Effects of PTH treatment on tibial bone of ovariectomized rats assessed by in vivo microCT. Osteoporosis International 20 1823-1835. (doi:10.1007/s00198-0090882-5)

Chappard D, Palle S, Alexandre C, Vico L \& Riffat G 1987 Bone embedding in pure methyl methacrylate at low temperature preserves enzyme activities. Acta Histochemica 81 183-190. (doi:10.1016/S0065-1281(87)80012-0)

Chavassieux PM, Arlot ME, Reda C, Wei L, Yates AJ \& Meunier PJ 1997 Histomorphometric assessment of the long-term effects of alendronate on bone quality and remodeling in patients with osteoporosis. Journal of Clinical Investigation 100 1475-1480. (doi:10.1172/JCI119668)

Compston JE, Mellish RW, Croucher P, Newcombe R \& Garrahan NJ 1989 Structural mechanisms of trabecular bone loss in man. Bone and Mineral 6 339-350. (doi:10.1016/0169-6009(89)90039-1)

Daval M, Diot-Dupuy F, Bazin R, Hainault I, Viollet B, Vaulont S, Hajduch E, Ferre P \& Foufelle F 2005 Anti-lipolytic action of AMP-activated protein kinase in rodent adipocytes. Journal of Biological Chemistry $28025250-25257$. (doi:10.1074/jbc.M414222200)

Dzamko NL \& Steinberg GR 2009 AMPK-dependent hormonal regulation of whole-body energy metabolism. Acta Physiologica 196 115-127. (doi:10.1111/j.1748-1716.2009.01969.x)

Fox J, Miller MA, Newman MK, Metcalfe AF, Turner CH, Recker RR \& Smith SY 2006 Daily treatment of aged ovariectomized rats with human parathyroid hormone (1-84) for 12 months reverses bone loss and enhances trabecular and cortical bone strength. Calcified Tissue International 79 262-272. (doi:10.1007/s00223-006-0108-1)

Han SM, Namkoong C, Jang PG, Park IS, Hong SW, Katakami H, Chun S, Kim SW, Park JY, Lee KU et al. 2005 Hypothalamic AMP-activated protein kinase mediates counter-regulatory responses to hypoglycaemia in rats. Diabetologia 48 2170-2178. (doi:10.1007/s00125-005-1913-1)
Hardie DG 2008 AMPK: a key regulator of energy balance in the single cell and the whole organism. International Journal of Obesity 32 (Suppl 4) S7-S12. (doi:10.1038/ijo.2008.116)

Hardie DG, Hawley SA \& Scott JW 2006 AMP-activated protein kinase development of the energy sensor concept. Journal of Physiology 574 7-15. (doi:10.1113/jphysiol.2006.108944)

Hardie DG, Carling D \& Gamblin SJ 2011 AMP-activated protein kinase: also regulated by ADP? Trends in Biochemical Sciences 36 470-477. (doi:10.1016/ j.tibs.2011.06.004)

Hawley SA, Davison M, Woods A, Davies SP, Beri RK, Carling D \& Hardie DG 1996 Characterization of the AMP-activated protein kinase kinase from rat liver and identification of threonine 172 as the major site at which it phosphorylates AMP-activated protein kinase. Journal of Biological Chemistry 271 27879-27887. (doi:10.1074/jbc.271.44.27879)

Hawley SA, Boudeau J, Reid JL, Mustard KJ, Udd L, Makela TP, Alessi DR \& Hardie DG 2003 Complexes between the LKB1 tumor suppressor, STRAD $\alpha / \beta$ and MO25 $\alpha / \beta$ are upstream kinases in the AMP-activated protein kinase cascade. Journal of Biology 2 28. (doi:10.1186/ 1475-4924-2-28)

Hawley SA, Pan DA, Mustard KJ, Ross L, Bain J, Edelman AM, Frenguelli BG $\&$ Hardie DG 2005 Calmodulin-dependent protein kinase kinase- $\beta$ is an alternative upstream kinase for AMP-activated protein kinase. Cell Metabolism 2 9-19. (doi:10.1016/j.cmet.2005.05.009)

Iida-Klein A, Zhou H, Lu SS, Levine LR, Ducayen-Knowles M, Dempster DW, Nieves J \& Lindsay R 2002 Anabolic action of parathyroid hormone is skeletal site specific at the tissue and cellular levels in mice. Journal of Bone and Mineral Research 17 808-816. (doi:10.1359/jbmr.2002. 17.5.808)

Iwaniec UT, Yuan D, Power RA \& Wronski TJ 2006 Strain-dependent variations in the response of cancellous bone to ovariectomy in mice. Journal of Bone and Mineral Research 21 1068-1074. (doi:10.1359/jbmr. 060402)

Jang WG, Kim EJ, Bae IH, Lee KN, Kim YD, Kim DK, Kim SH, Lee CH, Franceschi RT, Choi HS et al. 2011 a Metformin induces osteoblast differentiation via orphan nuclear receptor SHP-mediated transactivation of Runx2. Bone 48 885-893. (doi:10.1016/j.bone.2010.12.003)

Jang WG, Kim EJ, Lee KN, Son HJ \& Koh JT 2011 b AMP-activated protein kinase (AMPK) positively regulates osteoblast differentiation via induction of Dlx5-dependent Runx2 expression in MC3T3E1 cells. Biochemical and Biophysical Research Communications 404 1004-1009. (doi:10.1016/j.bbrc. 2010.12.099)

Jiang Y, Zhao JJ, Mitlak BH, Wang O, Genant HK \& Eriksen EF 2003 Recombinant human parathyroid hormone (1-34) [teriparatide] improves both cortical and cancellous bone structure. Journal of Bone and Mineral Research 18 1932-1941. (doi:10.1359/jbmr.2003.18.11.1932)

Jorgensen SB, Viollet B, Andreelli F, Frosig C, Birk JB, Schjerling P, Vaulont S, Richter EA \& Wojtaszewski JF 2004 Knockout of the $\alpha 2$ but not $\alpha 1$ 5'-AMP-activated protein kinase isoform abolishes 5-aminoimidazole-4carboxamide-1- $\beta$-4-ribofuranosidebut not contraction-induced glucose uptake in skeletal muscle. Journal of Biological Chemistry 279 1070-1079. (doi:10.1074/jbc.M306205200)

Kanazawa I, Yamaguchi T, Yano S, Yamauchi M \& Sugimoto T 2008 Metformin enhances the differentiation and mineralization of osteoblastic MC3T3-E1 cells via AMP kinase activation as well as eNOS and BMP-2 expression. Biochemical and Biophysical Research Communications 375 414-419. (doi:10.1016/j.bbrc.2008.08.034)

Kanazawa I, Yamaguchi T, Yano S, Yamauchi M \& Sugimoto T 2009 Activation of AMP kinase and inhibition of Rho kinase induce the mineralization of osteoblastic MC3T3-E1 cells through endothelial NOS and BMP-2 expression. American Journal of Physiology. Endocrinology and Metabolism 296 E139-E146. (doi:10.1152/ajpendo.90677.2008)

Kasai T, Bandow K, Suzuki H, Chiba N, Kakimoto K, Ohnishi T, Kawamoto S, Nagaoka E \& Matsuguchi T 2009 Osteoblast differentiation is functionally associated with decreased AMP kinase activity. Journal of Cellular Physiology 221 740-749. (doi:10.1002/jcp.21917)

Kola B, Hubina E, Tucci SA, Kirkham TC, Garcia EA, Mitchell SE, Williams LM, Hawley SA, Hardie DG, Grossman AB et al. 2005 
Cannabinoids and ghrelin have both central and peripheral metabolic and cardiac effects via AMP-activated protein kinase. Journal of Biological Chemistry 280 25196-25201. (doi:10.1074/jbc.C500175200)

Kola B, Boscaro M, Rutter GA, Grossman AB \& Korbonits M 2006 Expanding role of AMPK in endocrinology. Trends in Endocrinology and Metabolism 17 205-215. (doi:10.1016/j.tem.2006.05.006)

Lage R, Dieguez C, Vidal-Puig A \& Lopez M 2008 AMPK: a metabolic gauge regulating whole-body energy homeostasis. Trends in Molecular Medicine 14 539-549. (doi:10.1016/j.molmed.2008.09.007)

Lambers FM, Kuhn G, Schulte FA, Koch K \& Muller R 2012 Longitudinal assessment of in vivo bone dynamics in a mouse tail model of postmenopausal osteoporosis. Calcified Tissue International 90 108-119. (doi:10.1007/s00223-011-9553-6)

Lee YS, Kim YS, Lee SY, Kim GH, Kim BJ, Lee SH, Lee KU, Kim GS, Kim SW \& Koh JM 2010 AMP kinase acts as a negative regulator of RANKL in the differentiation of osteoclasts. Bone 47 926-937. (doi:10.1016/j.bone.2010.08.001)

Li CY, Schaffler MB, Wolde-Semait HT, Hernandez CJ \& Jepsen KJ 2005 Genetic background influences cortical bone response to ovariectomy. Journal of Bone and Mineral Research 20 2150-2158. (doi:10.1359/JBMR. 050819)

Lim CT, Kola B \& Korbonits M 2010 AMPK as a mediator of hormonal signalling. Journal of Molecular Endocrinology 44 87-97. (doi:10.1677/JME09-0063)

Lobo RA 2008 Metabolic syndrome after menopause and the role of hormones. Maturitas 60 10-18. (doi:10.1016/j.maturitas.2008.02.008)

Mai Q, Zhang Z, Xu S, Lu M, Zhou R, Zhao L, Jia C, Wen Z, Jin D \& Bai X 2011 Metformin stimulates osteoprotegerin and reduces RANKL expression in osteoblasts and ovariectomized rats. Journal of Cellular Biochemistry 112 2902-2909. (doi:10.1002/jcb.23206)

Minokoshi Y, Kim YB, Peroni OD, Fryer LG, Muller C, Carling D \& Kahn BB 2002 Leptin stimulates fatty-acid oxidation by activating AMP-activated protein kinase. Nature 415 339-343. (doi:10.1038/415339a)

Minokoshi Y, Alquier T, Furukawa N, Kim YB, Lee A, Xue B, Mu J, Foufelle F, Ferre P, Birnbaum MJ et al. 2004 AMP-kinase regulates food intake by responding to hormonal and nutrient signals in the hypothalamus. Nature 428 569-574. (doi:10.1038/nature02440)

Molinuevo MS, Schurman L, McCarthy AD, Cortizo AM, Tolosa MJ, Gangoiti MV, Arnol V \& Sedlinsky C 2010 Effect of metformin on bone marrow progenitor cell differentiation: in vivo and in vitro studies. Journal of Bone and Mineral Research 25 211-221. (doi:10.1359/jbmr.090732)

Parfitt AM, Drezner MK, Glorieux FH, Kanis JA, Malluche H, Meunier PJ, Ott SM \& Recker RR 1987 Bone histomorphometry: standardization of nomenclature, symbols, and units. Report of the ASBMR Histomorphometry Nomenclature Committee. Journal of Bone and Mineral Research 2 595-610. (doi:10.1002/jbmr.5650020617)

Quinn JMW, Tam S, Sims NA, Saleh H, McGregor NE, Poulton IJ, Walker EC, Scott J, Kemp BE, Gillespie MT et al. 2009 Mice lacking AMP-activated kinase (AMPK) subunits $\beta 1$ or $\beta 2$ have low bone mass, while AICAR acts AMPK-independently to increase osteoclast formation. Bone 44 S136-S136. (doi:10.1016/j.bone.2009.01.299)

Quinn JM, Tam S, Sims NA, Saleh H, McGregor NE, Poulton IJ, Scott JW, Gillespie MT, Kemp BE \& van Denderen BJ 2010 Germline deletion of AMP-activated protein kinase $\beta$ subunits reduces bone mass without altering osteoclast differentiation or function. FASEB Journal 24 275-285. (doi:10.1096/fj.09-137158)

Recker RR, Bare SP, Smith SY, Varela A, Miller MA, Morris SA \& Fox J 2009 Cancellous and cortical bone architecture and turnover at the iliac crest of postmenopausal osteoporotic women treated with parathyroid hormone 1-84. Bone 44 113-119. (doi:10.1016/j.bone.2008.09.019)

Shah M, Kola B, Bataveljic A, Arnett TR, Viollet B, Saxon L, Korbonits M \& Chenu C 2010 AMP-activated protein kinase (AMPK) activation regulates in vitro bone formation and bone mass. Bone 47 309-319. (doi:10.1016/ j.bone.2010.04.596)
Stapleton D, Mitchelhill KI, Gao G, Widmer J, Michell BJ, Teh T, House CM, Fernandez CS, Cox T, Witters LA et al. 1996 Mammalian AMP-activated protein kinase subfamily. Journal of Biological Chemistry 271 611-614. (doi:10.1074/jbc.271.45.28445)

Steinberg GR \& Kemp BE 2009 AMPK in health and disease. Physiological Reviews 89 1025-1078. (doi:10.1152/physrev.00011.2008)

Tezval M, Banhardt A, Sehmisch S, Kolios L, Schmelz U, Stuermer KM \& Stuermer EK 2011a The effects of parathyroid hormone applied at different regimes on the trochanteric region of the femur in ovariectomized rat model of osteoporosis. Journal of Osteoporosis 2011. In press. (doi:10.4061/ 2011/363617)

Tezval M, Serferaz G, Rack T, Kolios L, Sehmisch S, Schmelz U, Tezval H, Stuermer KM \& Stuermer EK $2011 b$ Effect of parathyroid hormone on hypogonadism induced bone loss of proximal femur of orchiectomized rat. World Journal of Urology 29 529-534. (doi:10.1007/s00345-011-0652-9)

Turner RT, Vandersteenhoven JJ \& Bell NH 1987a The effects of ovariectomy and $17 \beta$-estradiol on cortical bone histomorphometry in growing rats. Journal of Bone and Mineral Research 2 115-122. (doi:10.1002/jbmr. 5650020206)

Turner RT, Wakley GK, Hannon KS \& Bell NH $1987 b$ Tamoxifen prevents the skeletal effects of ovarian hormone deficiency in rats. Journal of Bone and Mineral Research 2 449-456. (doi:10.1002/jbmr.5650020513)

Viollet B, Athea Y, Mounier R, Guigas B, Zarrinpashneh E, Horman S, Lantier L, Hebrard S, Devin-Leclerc J, Beauloye C et al. 2009 AMPK: lessons from transgenic and knockout animals. Frontiers in Bioscience: a Journal and Virtual Library 14 19-44. (doi:10.2741/3229)

Viollet B, Horman S, Leclerc J, Lantier L, Foretz M, Billaud M, Giri S \& Andreelli F 2010 AMPK inhibition in health and disease. Critical Reviews in Biochemistry and Molecular Biology 45 276-295. (doi:10.3109/10409238. 2010.488215)

Wade-Gueye NM, Boudiffa M, Laroche N, Vanden-Bossche A, Fournier C, Aubin JE, Vico L, Lafage-Proust MH \& Malaval L 2010 Mice lacking bone sialoprotein (BSP) lose bone after ovariectomy and display skeletal sitespecific response to intermittent PTH treatment. Endocrinology 151 5103-5113. (doi:10.1210/en.2010-0091)

Wu W, Ye Z, Zhou Y \& Tan WS 2011 AICAR, a small chemical molecule, primes osteogenic differentiation of adult mesenchymal stem cells. International Journal of Artificial Organs 34 1128-1136. (doi:10.5301/ijao. 5000007)

Xiao B, Sanders MJ, Underwood E, Heath R, Mayer FV, Carmena D, Jing C, Walker PA, Eccleston JF, Haire LF et al. 2011 Structure of mammalian AMPK and its regulation by ADP. Nature 472 230-233. (doi:10.1038/ nature09932)

Xue B \& Kahn BB 2006 AMPK integrates nutrient and hormonal signals to regulate food intake and energy balance through effects in the hypothalamus and peripheral tissues. Journal of Physiology 574 73-83. (doi:10.1113/ jphysiol.2006.113217)

Yamauchi T, Kamon J, Minokoshi Y, Ito Y, Waki H, Uchida S, Yamashita S, Noda M, Kita S, Ueki K et al. 2002 Adiponectin stimulates glucose utilization and fatty-acid oxidation by activating AMP-activated protein kinase. Nature Medicine 8 1288-1295. (doi:10.1038/nm788)

Yamauchi M, Kambe F, Cao X, Lu X, Kozaki Y, Oiso Y \& Seo H 2008 Thyroid hormone activates adenosine $5^{\prime}$-monophosphate-activated protein kinase via intracellular calcium mobilization and activation of calcium/calmodulin-dependent protein kinase kinase- $\beta$. Molecular Endocrinology 22 893-903. (doi:10.1210/me.2007-0249)

Zhen D, Chen Y \& Tang X 2010 Metformin reverses the deleterious effects of high glucose on osteoblast function. Journal of Diabetes and its Complications 24 334-344. (doi:10.1016/j.jdiacomp.2009.05.002)

\section{Received in final form 8 June 2012 \\ Accepted 14 June 2012 \\ Made available online as an Accepted Preprint 14 June 2012}

